\title{
The Influence of Management's Compliance to Appraisal Procedures at the Organizations and Institutions
}

\author{
Irene Aboagye Konadu, Philip Baidoo*, Philip Opoku Mensah \\ Faculty of Technology Education, University of Education, Winneba, Ghana \\ Email address: \\ konaduaboagyafia@yahoo.com (I. A. Konadu),mypennich@yahoo.com (P. Baidoo), philipopokumensah@gmail.com (P. O. Mensah) \\ ${ }^{*}$ Corresponding author
}

\section{To cite this article:}

Irene Aboagye Konadu, Philip Baidoo, Philip Opoku Mensah. The Influence of Management's Compliance to Appraisal Procedures at the Organizations and Institutions. American Journal of Operations Management and Information Systems. Vol. 5, No. 2, 2020 , pp. $20-24$. doi: 10.11648/j.ajomis.20200502.11

Received: October 24, 2019; Accepted: November 13, 2019; Published: May 18, 2020

\begin{abstract}
Organizations and various sectors in every country have their ways of appraising their staff but the purposes are virtually the same. However this study investigated managements' compliance to appraisal procedures at the Metropolitan Assemblies specifically at the Human Resource Section. The research design employed to characterize and analyzed the purpose of the study. Purposive sampling techniques were used to select the respondents. The sample size for the study was 25 made up of 5 management members and 20 of both Junior and senior staff. Questionnaire and interview guide were used to collect data from the respondents which was analyzed to generate frequencies and percentages with the help of Microsoft Excel. The study resulted that the appraisals influence on managerial tools that can be used to impact the attitudes of employees in an organization revealed that process of appraisal was in-effective which has embarked influence on the organisation, and their subordinates has a lesser attention insert.
\end{abstract}

Keywords: Human Resource Management, Appraisers, Investigated, Management, Organization

\section{Introduction}

Organizations and various sectors in every country have their ways of appraising their staff but the purposes are virtually the same. The nature of the organization and other related factors and conditions in the environment will show the type of appraisal system to be adopted. However appraisal is the process of assessing worth, value, quality of performance. It requires the employee and his or her transferring officer to plan the performance of the Appraises at the beginning of the year, review the performance after six months, analyze the factors affecting the performance, discuss developmental needs, have performance counseling and share the rating at end of the period. Other researcher has made a lot of contribution on staff appraisal in various fields' shows different reasons for staff appraisal. [1] "Performance appraisals provide a vehicle for managing and developing human resources by virtue of linkages to sub functions such as training, compensation, internal mobility and decisions. Mullins [2] states that, a comprehensive appraisal system can provide the basis for key managerial decisions, such as those related to the allocation of duties and responsibilities, pay, delegation, levels of supervision, promotions, training and developmental needs. Cole [3] contend that various models of performance appraisal have been provided by the management experts and organizations use them according to their organization's mission, structure and manpower.

People appraise conditions and situations mostly in unstructured and informal ways. Most performance appraisals in organizations take a formal and structured form. It may however start as informal observation and discussions to be used for the formal system maintain that appraisal is a formal system. [4-6] Formal employee appraisal is a formal organized process conducted on a systematic basis in order to enable a comparison between the expected individual (group) performance and real performance [7]. However [5] "Performance appraisal is formal structured system of measuring and evaluating employees' job related behavior and outcomes to discover how and why the employee is presently performing on the job. [5] How the employee can perform more effectively in the future so that the employee, 
organization and society, all benefits. The paper further states that "The focus of performance appraisal is measuring and improving the actual performance of the employee and also the future potential of the employee". This stresses the need for a good performance appraisal system to be futuristic in nature by incorporating in it the future career development of the employee and unearthing other potentials of the workers by the study [8]. It can also be seen as a formal organizational mechanism for controlling the performance of work tasks on a rational, subjective and continuous basis. In assessing the desirability of developing formal performance appraisal systems, [9] contends that organizations must answer several important questions. A decision must be made about why performance is to be evaluated. They should also decide which employees are to be evaluated. Formal appraisals do not apply to all types of employees. Performance appraisal is also seen as a way of identifying strength and weaknesses that can be harnessed for development of the employee. This also brings out the need for organizations to incorporate futuristic needs of their employees. [10] This is confirmed in that "The goal of performance appraisal is to assess and summarize past performance, and develop future work, performance goals and expectations". [11] contend that Performance appraisal is the measurement of work and its results by using the scale and index, that we can measure the desired quantity and quality with precision and free of personal judgments and vague criteria of evaluation. They assert that the measuring ability of performance appraisal should be based on a criterion which will help in avoiding personal biases of the appraiser to produce right information about the employee (appraise).

They however left out the issue of employee development which is crucial in the use of appraisal results. [12] performance appraisal is a process to improve employees' work performance by helping them to realize and use their full potential in carrying out the organization's mission and to provide information to employees and managers for use in making work relation decision. [13] Also assert that performance appraisal is a process that involves determining and communicating to employees how they are performing their jobs and establishing a plan for improvement. [14] shares a similar view by defining performance appraisal as the systematic evaluation of the employees' job performance and also their potential for growth and development. [15] on their part explain appraisal in organizations by stating that "It is a means of promoting, through the use of certain techniques and procedures, the organizations ability to accomplish its mission of maintaining and improving what it provides while at the same time seeking to maintain or enhance staff satisfaction and development". [16] share this view by explaining that performance management is the system through which organizations set work goals, determine work standards, assign and evaluate work, provide performance feedback, determine training and development needs and distribute rewards. [17] suggest that performance appraisal includes all formal procedures used to evaluate personalities, contributions and potentials of members in a working organization. It is a continuous process to secure information necessary for making correct and objective decisions on employees. They summarize it as "the systematic evaluation of the individual with respect to his performance on the job and his potential for development". [18] Staff appraisal systems are about documenting the quality of staff performance, helping them improve and holding them accountable for their work.

However in view of this the researcher interned to studied and investigated the appraisals influence on managerial tools that can be used to impact the attitudes of employees to make them more productive and effective. And the characterized and analyzed data results which was put in place a proper means of appraisal system which is performed at the right time, frequency and purpose, it will help to identify the effectiveness of the staff and the lapses that need to be addressed.

\section{Methodology}

The design used in this study has "learning by participation" as its main objective. It implies that, the researchers and individual identifies a problem; finding the courses and recommendation, advice for an intervention mechanism to solve that problem. The purpose of this study that necessitated the choice research to enhance themanagement's compliance to appraisal procedures at the metropolitan assemblies. When the procedures involved in the use of research method were thoroughly examined, it fitted the topic for this study, hence its adoption. In order to solicit information from the staff of the organization, the basic instruments used were Interview and questionnaire. On the collection of data, a semi-structured interview schedule was arranged with the staff members, during which a lot of information were gathered to get information on appraisal issues that were pertaining within the establishment. A questionnaire was used to further solicit the causes of gaps within the appraisal system. The research questions were the basis on which all the data gathered for the study were characterised and analysed. The data analysis was done with the aid of the descriptive statistics approach emphasising mainly on the percentage (\%) technique. Other data from the interviews were analysed with the view of Enhancingmanagement's Compliance to Appraisal Procedures.

\section{Results}

\subsection{Post Intervention Questionnaire from Management}

The five management members were asked to indicate whether they had appraised their subordinates in recent times that was with reference to the post intervention period. In their response, all the respondents $(100 \%$; $n=5)$ responded Yes as indicated by table 1 . 
Table 1. Recent appraisal of subordinates by management.

\begin{tabular}{lll}
\hline Respones & Frequency & Percentage\% \\
\hline Yes & 5 & 100 \\
No & - & - \\
Total & 5 & 100 \\
\hline
\end{tabular}

\subsection{Training Needs}

The respondents were asked to indicate if they held discussions with their subordinates after they had filled the appraisal forms on the training needs the subordinates would require in order to facilitate their work. In their response, all the respondents $(100 \% ; n=5)$ responded yes to indicate that they really discussed the training needs of their subordinates after those needs were identified form the appraisal questions answered, as illustrated by table 2 .

Table 2. Training needs discussion.

\begin{tabular}{lll}
\hline Response & Frequency & Percentage\% \\
\hline Yes & 5 & 100 \\
No & - & - \\
Total & 5 & 100 \\
\hline
\end{tabular}

\subsection{Questionnaire Administered to Employees}

The staff, numbering 20, were asked to indicate whether they had been appraisal after the intervention. In their response, all of them $(100 \% \mathrm{n}=20)$ indicted that they had be recently appraised. This goes to confirm the assertion raised by the management that they had appraised their subordinate as shown in table 3 .

Table 3. Management subordinate.

\begin{tabular}{lll}
\hline Response & Frequency & Percentage $\%$ \\
\hline Yes & 20 & 100 \\
No & - & - \\
Total & 20 & 100 \\
\hline
\end{tabular}

\subsection{Staff Involvement of Appraisal}

To confirm the assertion made by the management on the involvement of their subordinates in the appraisal process, the staff were asked to indicate their involvement in the appraisal process. In their response all respondents $(100 \%$; $\mathrm{n}=20$ ) indicated that they had discussions with their superiors before answering the appraisal questions as shown in table 4 . This actually confirm what their superior said.

Table 4. Employee involvement in appraisal.

\begin{tabular}{lll}
\hline Response & Frequency & Percentage\% \\
\hline Yes & 20 & 100 \\
No & - & - \\
Total & 20 & 100 \\
\hline
\end{tabular}

\begin{tabular}{ll|l}
\hline Response & frequency & percentage $\%$ \\
\hline $\begin{array}{l}\text { I only answered questions without } \\
\text { discussions }\end{array}$ & - & - \\
$\begin{array}{l}\text { Had discussions with my superior before } \\
\text { answering }\end{array}$ & 20 & 100 \\
$\begin{array}{l}\text { Was left alone to answer the question } \\
\begin{array}{l}\text { My superior answered on my behalf } \\
\text { TOTAL }\end{array}\end{array}$ & - & - \\
\hline
\end{tabular}

\subsection{Satisfaction of Appraisal Procedure}

After the staff had indicated that they had observed significant change in the appraisal procedures, they were further interrogated to indicate whether they were appreciative of the current procedural trends of the appraisal. In their response, all the respondents $(100 \% ; n=20)$ opined that they were really satisfied with the new [procedures for appraisal as show in table 5 .

Table 5. Satisfaction of appraisal procedures.

\begin{tabular}{lll}
\hline Response & Frequency & Percentage\% \\
\hline Yes & 20 & 100 \\
No & - & - \\
Total & 20 & 100 \\
\hline
\end{tabular}

\section{Discussions}

\subsection{Pre Intervention Interview with the Staff}

In this section, evidence of the management noncompliance to appraisal procedures were sought from staff. All the twenty (20) staff were interviewed and the outcome of the interview indicated that majority of the respondents $(60 \% ; n=12)$ were not motivated to work. The rest of the respondents $(40 \% ; n=8)$ indicated that they were motivate to work. As to what motivate the minority, the interview revealed that, majority of them $(75 \% ; n=6)$ were motivated by external influences they received within the sector. The remaining respondents $(25 \% ; n=2)$ were of the view that, their source of motivation were strictly intrinsic. On the appraisal procedures, all the respondents $(100 \% ; n=20)$ indicated that they have gone through some sort of appraisal and the appraisal was done by their supervisors. On the appraisal process, it was revealed that, all the staff $(100 \%$; $\mathrm{n}=20$ ) went through a common process in the appraisal system by filling an appraisal form and then supervisors also filling their portion for further submission to Human Resource Department. A further interrogation on training after appraisal indicated that, all the respondents $(100 \%$; $\mathrm{n}=20$ ) are not given any form of on-the-job training after appraisal.

\subsection{Pre Intervention Interview with the Management}

In all five (5) management members were interviewed to solicit information on staff appraisal issues. The interview revealed that; all the respondents $(100 \% ; n=5)$ appraised their subordinates and the appraisal is done annually, with the reason for appraisal being to monitor progress of work. As for the appraisal procedures, all the respondents $(100 \% ; n=5)$ outlined the filling of appraisal forms by the subordinates followed by supervisor filling their portion.

\subsection{Subordinate Involvement in the Appraisal Process}

The respondents were tasked to indicate how they involved their subordinates in the appraisal process that took place recently after the intervention. In this response all 
respondents $(100 \% ; n=5)$ indicated that they had discussions with their subordinates and guided them to answer all appraisal questions.

\subsection{Change in Appraisal Procedures}

The respondents were asked to indicate whether they had realised any change in the appraisal procedures as compared to what was previously done before the interventions. In their response, all the respondents $(100 \% ; n=5)$ said Yes they had observed a difference in the appraisal procedures

\subsection{Satisfaction of Current Appraisal Procedures}

Here, the respondents were asked if they were satisfied with the current appraisal procedure as compared to what was practiced before interventions. In their response, it was not surprising to see that all the respondents $(100 \% ; n=5)$ indicated that they were very satisfied with the current appraisal procedure.

\subsection{Appraisal Supervisor}

To find out who actually did the appraisal of the staff, the staff was asked to indicate whether the appraisal were done by their immediate superiors. In their response, all the respondent $(100 \% ; n=20)$ said yes the appraisal was supervised by their immediate superiors. This also confirms what the management said concerning their supervision of the appraisal process.

\subsection{Discussion of Training Needs}

To confirm the managements statement of discussing training needs of their subordinates after appraisal. The staffs was subjected to a yes or no question on whether their superiors really discussed their training needs after filling the appraisal form. In their response all respondents $(100 \%, n=20)$ indicated that they had discussion on their training needs with their subordinate after appraisal.

\subsection{Change in Appraisal Procedures}

Here, the respondents were asked to indicate whether they had been any form of change in the procedure for staff appraisal as compared with the previous ones they had gone through. In their response, all the respondents $(100 \% ; n=20)$ indicated that they had really seen a significant change in the appraisal procedure

\section{Conclusions}

The study sought to enhance and investigated the appraisals influence on managerial tools that can be used to impact the attitudes of employees in an organization. However Interviews and questionnaires were used to obtained all the necessary evidence. There was a Critical characterised and analysis that revealed the following as pertaining organisation;

1. The work output is not encouraging.

2. The process of appraisal was in-effective which has embarked influence on the organisation, and

3. Management area involving their subordinates has a lesser attention insert and Staff are not motivate to work well.

\section{References}

[1] Moulik, S. R., \& Mazumder, S. (2012). Exploring the relationship between perceive uses of appraisal and Satisfaction in the Indian IT sector: An empirical study. International Journal and Social Research (UBSR), 2 (5), 63 76.

[2] Mullins, L. J. (1996). Management and organisational behaviour. London: Pitman Publishing.

[3] Cole, G., A. (2002). Personnel and human resource management. London: Biddles Ltd Guildford and King's Lynn.

[4] Giangreco, A., Carugati, A., Sabastiano, A., \& Altamimi, H. (2012). War outside, ceasefire inside: An analysis of the performance appraisal system of a public hospital in a zone of conflict. Evaluation and Program Planning, 35 (1), 13-18.

[5] Kumbhar S. A. (2011). Impact of performance appraisal on corporate profitability Indian Streams Research Journal, 1 (4), 10-18.

[6] Cole, G. A. (2004). Management, theory and practice. London: Thomson Practice.

[7] Mullen, B., \& Cooper, C. (1994). The relation between group cohesions and performance. An integration. Psychological Bulletin, 115, 210-27.

[8] Kouzes, J. M., \& Posner, B. Z. (2002). The leadership challenge (3rd ed.). San Francisco: Jossey-Bass.

[9] Stoner, J. A. F. (1982). Management (2nd ed.). New Jersey: Prentice-Hall. Strebler, M. T., Robinson, D., \& Bevan, S. (2001). Performance review: Balancing objectives and content. Institute of Studies, IES Report 370.

[10] Akinyele, S. T. (2010). Performance appraisal systems in private universities in Nigeria: A study of Crawford University, Igbesa-Nigeria. Global Journal of Management and Business Research, 10 (6), 21-30.

[11] Ali, S. B., Mahdi, A., \& Malihe, J. (2012). The effect of employee's performance appraisal procedure on their intrinsic motivation. Pakistan: Human Resource Academic Society.

[12] Cascio, F. W. (1992). Managing human resources (3rd ed.). New York McGraw-Hill. Inc.

[13] Rue, L. W., \& Byars, L. L. (1995). Management skills and application (7th ed.). Chicago: Irwin.

[14] Chatterjee, B. (1999). Human resource management. A contemporary text. New Delhi: Sterling Pub Pvt Ltd.

[15] Poster, C., \& Poster, D. (1992). Staff appraisal: A guide to training. New York: Routledge.

[16] Briscoe, D. B., \& Claus, L. M. (2008). Employee performance management: Policies and practices in multinational enterprises. In P. W. Budwah, \& A. Denisi (Eds.). Performance management system: A global perspective. Abingdon: Routledge. 
[17] Rai, U. K., \& Shrivastava, P. (2012). Performance appraisal in Indian banks. A Journal of Management and Publications. Retrieved $11 / 09 / 2014$

http://www.integraluniversity.ac.in/net/journals.
[18] Stronge, J. H. (2006b). Performance evaluation and school improvement: improving the educational landscape. In J. H. Stronge (Eds.), Evaluating staff: A guide to current thinking and best practice (2nd ed.). Thousand Oaks, CA: Corwin Press. 